\title{
Should we send our kids to the gym?
}

\author{
Eduardo Pimenta
}

Hypertension Research (2010) 33, 880-882; doi:10.1038/hr.2010.118; published online 15 July 2010

$\mathrm{H}$ ypertension and diabetes mellitus are the two major risk factors for cardiovascular morbidity/mortality and end-stage renal disease, and they commonly present together. Worldwide, the prevalence of diabetes for all age groups was estimated to be $2.8 \%$ in 2000 and is projected to be $4.4 \%$ in $2030 .{ }^{1}$ Regarding hypertension, $26.4 \%$ of the adult population had hypertension in 2000 and $29.2 \%$ will have hypertension in 2025 . $^{2}$ In absolute numbers, 171 and 972 million people had diabetes and hypertension, respectively, in 2000. In 2030, 366 million people will have diabetes, and, in 2025, 1.56 billion people will have hypertension. ${ }^{1,2}$

Physical activity is recommended to improve and maintain health, ${ }^{3}$ as it is regarded as both a treatment and a prevention tool for both hypertension and diabetes. All healthy adults aged 18-65 years should do moderate-intensity aerobic exercise for a minimum of $30 \mathrm{~min} 5$ days/week or vigorous-intensity aerobic exercise for a minimum of $20 \mathrm{~min} 3$ days/week to promote and maintain health. ${ }^{3}$

The alarming obesity rates among children and adolescents have called attention to physical activity in childhood. ${ }^{4,5}$ Children's participation in free play and school-based physical education programs has declined during recent years, and children no longer have adequate levels of healthy activity. ${ }^{5}$ Schools have been asked to increase physical education frequency and promote physical activities not only during school time, but also before and after school. ${ }^{5}$ The benefits of exercise to children are also related to weight management.

Dr E Pimenta is at the Endocrine Hypertension Research Centre and Clinical Centre of Research Excellence in Cardiovascular Disease and Metabolic Disorders, University of Queensland School of Medicine, Princess Alexandra Hospital, 5th Floor, Ipswich Road, Woolloongabba, Brisbane, Queensland 4102, Australia.

E-mail: e.pimenta@uq.edu.au
The benefits of physical activity in children and adolescents may impact chronic disease in their adult years. In this issue of Hypertension Research, Fernandes and Zanesco ${ }^{6}$ analyzed the relationship between current and earlier physical activity in childhood/adolescence with prevalence of hypertension and type 2 diabetes in adulthood. After interviewing 1436 adults, they found that male gender, young age and higher formal education were associated with greater levels of physical activity, and obesity/overweight status was associated with lower levels of physical activity. Surprisingly, physical activity practices during childhood/ adolescence, but not current activity, were associated with a lower prevalence of hypertension and diabetes.

Although these results are interesting, the study design must be evaluated. The weaknesses include its retrospective design and the poor accuracy of the reported data. The information provided about physical activity in childhood/adolescence was self-reported using a two-question questionnaire. The authors were not able to quantify the level of exercise. 'Sport activity outside school' was assumed by the authors to be a supervised and structured physical activity. To try to minimize the bias of self-reported information, authors interviewed subjects twice, 2 weeks apart, using different interviewers.

In spite of the weaknesses, two important messages can be extracted from the study. First, the fact that current physical activity was not associated with lower prevalence of hypertension and diabetes shows that prevention is of utmost importance. Second, the study supports the concept that youths should participate in organized programs for physical activity at early ages. These programs should comprise exercises structured to the specific physical, emotional and cognitive needs of the participants and should be created and conducted under the close supervision of qualified professionals.
Starting organized physical activity at an early age will help youths to create health habits that will likely continue throughout their lives.

Nostalgic adults have complained that outdoor activities have been replaced by indoor confined adventures: bicycles and balls are no longer more exciting than virtual journeys provided by video games and the Internet. Unfortunately, free activities have substantially decreased in most cities mostly because of urban risks, such as increased traffic, and to limited spaces such as parks and recreation areas dedicated to these activities. Outdoor free play activities are important parts of childhood and should be encouraged. However, free playtime provides a lower level of physical exercise compared with organized and structured activities. A randomized-controlled study evaluated if daily physical activity levels are increased by increasing children's outdoor free playtime. ${ }^{7}$ Accelerometers were used in 32 preschool children before and after intervention. A group of children received additional 30-min periods of outdoor free playtime per day for 2 days and the other group followed their normal classroom schedule. There were no differences between groups in the total daily and during the school day percent of time spent in moderate to vigorous physical activity.

Participation in organized and structured physical activities carries not only physical and social benefits for children, but also risks (Figure 1). The age of the participant must be taken into account to provide maximum benefits and minimal risks. These activities, if not appropriate, may have negative effects on growth and maturation of children. ${ }^{8}$ For instance, reports of gymnasts with short stature and ballet dancers with lean body types and late menarche are common. A child may develop feelings of failure and frustration if demands exceed cognitive and physical development. 


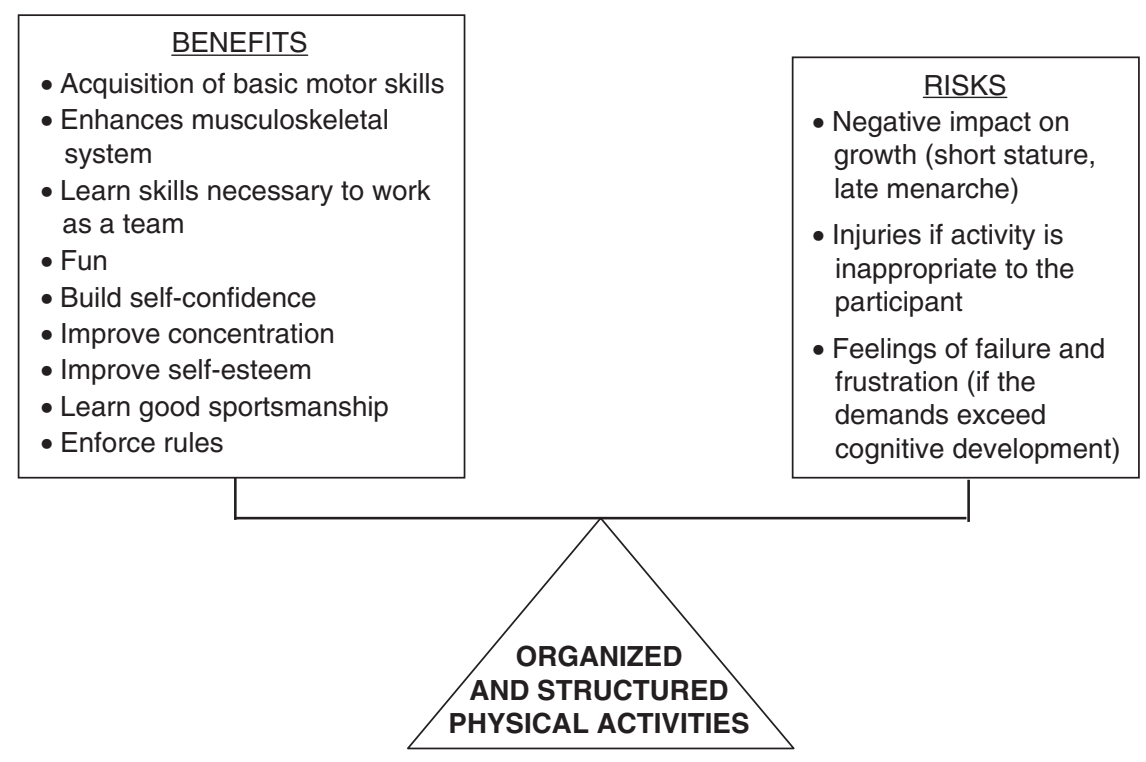

Figure 1 Risks and benefits of exercise in children.

Children should ideally have access to both unstructured free play and organized activities. Multidisciplinary teams including pediatricians, physical educators, psychologists and other healthcare professionals are necessary to organize and implement safe physical activities. These activities must be enjoyable and fit with the child's and family's lifestyle to facilitate adherence to the program. Careful consideration must be given to selecting the most appropriate intensity, frequency, duration and modality of exercise.

There is no consensus about how much physical activity children and adolescents need to stay healthy and prevent future diseases. In general, school-age youths should do $60 \mathrm{~min}$ daily or more of moderate- to vigorous-intensity (5-8 metabolic equivalents) activity that is enjoyable and developmentally appropriate. ${ }^{9}$ Activities that emphasize cardiovascular and muscular endurance and muscular strength and those that involve bearing weight are preferred. Sedentary behaviors such as watching television, using a computer, playing video games and talking on the telephone should be reduced to $<2 \mathrm{~h}$ per day.

The finding presented by Fernandes and Zanesco ${ }^{6}$ - that physical activity in youth is related to lower prevalence of diabetes in adulthood-is supported by earlier studies. Dwyer et al. ${ }^{10}$ prospectively followed 647 children (aged 7-15 years) who participated in the Australian Schools Health and Fitness Survey. They underwent a submaximal cardiorespiratory fitness test and estimation of lean body mass in 1985. Insulin resistance, obesity and changes in cardiorespiratory fitness were reassessed in 2004-2006. In that study, a lower level of cardiorespiratory fitness as a child was associated with increased odds of obesity and insulin resistance as an adult. Furthermore, a decline in fitness level from childhood to adulthood was associated with increased obesity and insulin resistance. Considering cardiorespiratory fitness as a measurement of physical activity, we can conclude that a decline in physical activity from childhood to adulthood is associated with metabolic changes in adulthood.

Maintenance of physical activity from childhood to adulthood is a challenge. In Fernandes and Zanesco's study, ${ }^{6}$ individuals that were currently physically active were more engaged in exercise in both childhood and adolescence. In the study carried out by Dwyer et al., ${ }^{10}$ fit children were more likely to be fit adults. The simplest theory is that active children will become active adults because they become accustomed to exercising. However, more complex mechanisms that determine physical activity have been studied. A decline in physical activity with chronological age not only in human beings, but also in all species, suggests a biological basis for these patterns. ${ }^{11}$ Dopamine release, puberty-related changes (in human beings, a significant decline in physical activity occurs during adolescence) and genetic heritability have been tested to explain the biological basis of tendencies toward physical activity. ${ }^{11}$

Evidence has accumulated to prove the advantages of physical activity at all ages. Not only adults, but also children and adolescents benefit from structured activities, and programs that encourage exercise earlier in life have to be supported. No one argues the benefits of physical activity anymore. Researchers should now work on a more complex question that is commonly asked: How can we improve the adherence to physical activities?

\section{CONFLICT OF INTEREST}

The author declares no conflict of interest.

1 Wild S, Roglic G, Green A, Sicree R, King H. Global prevalence of diabetes: estimates for the year 2000 and projections for 2030. Diabetes Care 2004; 27: 1047-1053.

2 Kearney PM, Whelton M, Reynolds K, Muntner P, Whelton PK, He J. Global burden of hypertension: analysis of worldwide data. Lancet 2005; 365 : 217-223.

3 Haskell WL, Lee IM, Pate RR, Powell KE, Blair SN, Franklin BA, Macera CA, Heath GW, Thompson PD, Bauman A. Physical activity and public health: updated recommendation for adults from the American College of Sports Medicine and the American Heart Association. Circulation 2007; 116: 1081-1093.

4 Daniels SR, Jacobson MS, McCrindle BW, Eckel RH, Sanner BM. American Heart Association Childhood Obesity Research Summit: executive summary. Circulation 2009; 119: 2114-2123.

5 Pate RR, Davis MG, Robinson TN, Stone EJ, McKenzie TL, Young JC. Promoting physical activity in children and youth: a leadership role for schools: a scientific statement from the American Heart Association Council on Nutrition, Physical Activity, and Metabolism (Physical Activity Committee) in collaboration with the Councils on Cardiovascular Disease in the Young and Cardiovascular Nursing. Circulation 2006; 114: 1214-1224.

6 Fernandes RA, Zanesco A. Early physical activity promotes lower prevalence of chronic diseases in adulthood. Hyperts Res 2010; 33: 926-931.

7 Alhassan S, Sirard JR, Robinson TN. The effects of increasing outdoor play time on physical activity in Latino preschool children. Int J Pediatr Obes 2007; 2: $153-158$

8 Washington RL, Bernhardt DT, Gomez J, Johnson MD, Martin TJ, Rowland TW, Small E, LeBlanc C, Krein C, 
Malina R, Young JC, Reed FE, Anderson S, Bolduc S, Bar-Or O, Newland H, Taras HL, Cimino DA, McGrath $J W$, Murray RD, Yankus WA, Young TL, Fleming M, Glendon M, Harrison-Jones L, Newberry JL, Pattishall E, Vernon M, Wolfe L, Li S. Organized sports for children and preadolescents. Pediatrics 2001; 107: 1459-1462.
9 Strong WB, Malina RM, Blimkie CJ, Daniels SR, Dishman RK, Gutin B, Hergenroeder AC, Must A, Nixon PA, Pivarnik JM, Rowland T, Trost S, Trudeau F. Evidence based physical activity for school-age youth. J Pediatr 2005; 146: 732-737.

10 Dwyer T, Magnussen CG, Schmidt MD, Ukoumunne OC, Ponsonby AL, Raitakari OT, Zimmet PZ, Blair SN,
Thomson R, Cleland VJ, Venn A. Decline in physical fitness from childhood to adulthood associated with increased obesity and insulin resistance in adults. Diabetes Care 2009; 32: 683-687.

11 Eisenmann JC, Wickel EE. The biological basis of physical activity in children: revisited. Pediatr Exerc Sci 2009; 21: 257-272. 